\title{
La información como instrumento estratégico
}

\author{
Mg. Félix BELLEZA OCHOA
}

\section{RESUMEN}

Las organizaciones de hoy están en constante evolución y esa evolución las eleva a cambios cíclicos que son determinados por agentes externos e internos. Para mejorar la coordinación interna así como la integración de las unidades orgánicas será necesario entre otras cosas compartir información por medio de intranets y redes de información; sistemas de planeación de recursos de la empresa (ERP) y sistema de administración del conocimiento

A efectos de tomar un mejor conocimiento de estos temas le ofrecemos un resumen de estos aspectos publicados por Richard Daft en su libro Diseño y Teoría de Organización.

Las tres principales herramientas de la tecnología de la información para la coordinación interna son:

- Intranets.

- $\quad$ Planeación de recursos para la empresa (ERP); y

- Sistemas de administración de conocimientos.

\section{INTRANETS}

Son redes que conectan personas y departamentos dentro de una institución o empresa y entre las oficinas que la conforman; les permite compartir información y cooperar en sus proyectos.

El intranet es un sistema privado de comunicación dentro de las empresas que utiliza los estándares y protocolos de comunicación de Internet y de la red global pero es accesible solo a los empleados dentro de la organización así, los empleados pueden revisar expedientes o tomar información navegando en el sitio con un Web Browser Estándar y tocando vínculos.

Como la intranets está basada en la red, pueden tener acceso desde cualquier tipo de computadora o estación de trabajo. 
Actualmente muchas empresas han cambiado sus sistemas de información de sus empleados y de sus ejecutivos, por la intranet y de esta manera ofrecer acceso fácil a todos los que la recibieran.

Las intranets mejoran las comunicaciones internas y encuentran la información escondida. También permite a los empleados poder estar en contacto con lo que pasa en la organización; encontrar rápida y fácilmente la información necesitada, compartir ideas y trabajar juntos en proyectos.

Las más avanzadas intranets conectan a más de 100,000 puestos de trabajo, de miles de sitios ofreciendo información tales como investigación de mercados, análisis de los componentes de los competidores, desarrollo de proyectos y otros. También permite a sus vendedores el rápido acceso a las ventas, clientes y coordinar entre ellos o en todo caso localizar un experto dentro de la empresa para ayudarse con promociones, costos o anuncios de nuevos productos.

\section{PLANEACIÓN DE RECURSOS PARA LA EMPRESA (ERP)}

Un número creciente de compañías están implantando sistemas de información a gran escala, que toman una visión amplia de las actividades de la organización. Este sistema de ERP colecciona, procesa y provee información acerca de todo lo relacionado con la compañía, incluye el proceso de órdenes y pedidos, diseño del producto, compras, inventarios, manufacturación o producción, distribución, recursos humanos, recibo de pagos y pronósticos de demandas futuras. Un ERP puede servir como soporte para toda la organización al integrar y optimizar todos los procesos de negocios.

Estos sistemas conectan todas estas áreas de actividad dentro de una red como por ejemplo:

Cuando un vendedor toma un pedido el sistema ERP de inmediato lo revisa para saber como este pedido va a impactar en los niveles de inventario, horarios, recursos humanos, compras y distribución. 


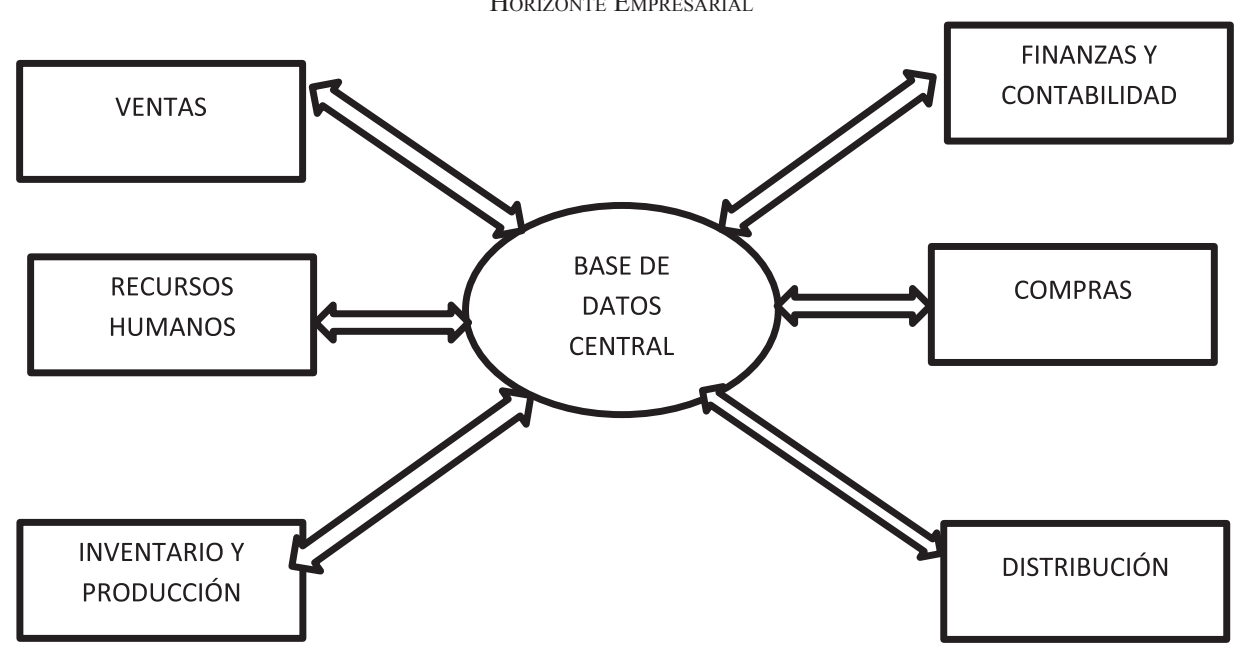

El sistema duplica los procesos organizacionales en un software, y a los empleados por medio de un proceso paso a paso.

También automatiza todo lo que es posible. Por ejemplo el software de planeación de recursos para la empresa (ERP), puede automáticamente enviar un cheque de cuentas por pagar tan pronto como el empleado confirma que los productos son recibidos en el inventario; enviar de inmediato desde la computadora una orden de compra después que un administrador la autoriza, o un horario de producción a la planta más apropiada enseguida de que un pedido es recibido.

Sabiendo que los sistemas integran datos acerca de todos los aspectos de la información, los administradores y empleados en todos los niveles pueden darse cuenta de cómo las decisiones y acciones de una parte de la organización afectan a otras, utilizando esta información para obtener mejoras en las decisiones. La ERP provee la clase de información obtenida por los sistemas de procesos de transacción, y también suministra información de los sistemas de reporte, sistemas de apoyo a las decisiones, sistemas de información para ejecutivos. La clase es que el ERP reúne todos estos sistemas para que el personal sea capaz de observar todo, y actuar rápidamente ayudando a la organización a estar más preparada y más competitiva.

\section{ADMINISTRACIÓN DEL CONOCIMIENTO}

Las organizaciones que pretenden ir a la vanguardia en los sistemas de tecnología de la información señalan como objetivo principal la administración del conocimiento; para lo cual deben apoyar los esfuerzos en administrar y reforzar los conocimientos organizacionales, tener un mayor acceso a la información por sí mismo no es útil, a menos que la información sea implantada para ampliar los objetivos y el éxito de la organización. El aumento del capital intelectual es la principal manera con la cual las organizaciones miden sus valores. Así los 
administradores ven el conocimiento como un elemento importante para dirigir o administrar.

Los procesos internos así como los recursos de la empresa entre los cuales juegan un papel importante las personas; éstas para aprender y cambiar, las organizaciones deben efectivamente adquirir, crear o transferir conocimientos dentro la organización y modificar sus actividades para reflejar nuevos conocimientos e intuiciones.

La administración del conocimiento es una forma de pensar para organizar y compartir los recursos creativos e intelectuales de la empresa. Esto se refiere a los esfuerzos para encontrar sistemáticamente, organizar y tener disponible el capital intelectual de la institución o empresa, así como fomentar una cultura de continuo aprendizaje y el compartir conocimientos; de esta forma las actividades organizacionales se construyen sobre lo que ya se conoce. El capital intelectual de la empresa es la suma de sus conocimientos, experiencias, comprensión, relaciones, procesos, innovaciones y descubrimiento. Pero la mayor parte de los conocimientos están dentro de los límites de la organización, tocando los conocimientos de expertos foráneos, lo cual es importante también porque atrae nuevos conocimientos a la empresa, los mismos que pueden combinarse con el conocimiento existente para enfrentar problemas y oportunidades y convertir a la organización en más competitiva. También la tecnología de información juega un papel importante en los conocimientos de los administradores al permitir almacenar y diseminar datos e información por medio de la organización. La tecnología de la información es sólo una pieza en un gran rompecabezas. Un sistema completo de conocimiento de los administradores incluyendo no solamente procesos para capturar y almacenar conocimientos y el organizarlos para un fácil acceso, sino también una manera para generar nuevos conocimientos, por medio del aprendizaje, y compartir conocimientos por todo el país. Cuando hablamos de conocimiento no solo es la acumulación de datos sino también de información, esto es, incluye a ambos y su utilización.

Los datos son simples, hechos absolutos y figuras o números que entre ellos mismos son de poca utilidad pero si los datos son procesados y al ser conectados con otros datos pueden convertirse en información susceptible de ser utilizada, por ejemplo una empresa puede tener datos que nos muestran que el $30 \%$ de sus productos son vendidas a clientes de un país "X". Estos datos por sí solos no serían de mucha utilidad, pero si son procesados y convertidos en información, seguramente que sí tendríamos que conectarlos con otros datos por ejemplo que 9 de 10 productos vendidos son comprados por personas de más de 60 años. En este caso, la información son datos que han sido conectados con otros datos y convertidos en un contexto útil para uso específico. El conocimiento va un poco más lejos, es una conclusión obtenida de la información después 
de ser conectada a otra información y comparada con lo que se conoce. El conocimiento opuesto de la información y a los datos siempre tiene un factor humano. Los libros pueden tener información, pero la información se convierte en conocimientos, solamente cuando la persona lo absorbe y lo utiliza.

Las organizaciones tratan con conocimiento explícito e implícito y conocimiento tácito. El conocimiento explícito es formal y sistemático, que puede ser codificado, escrito y pasado a otros empleados en documentos con instrucciones generales. El conocimiento tácito es comúnmente difícil de poner en palabras, el conocimiento tácito está basado en la experiencia personal, reglas, intuición y conocimientos. Esto incluye experiencia profesional de saber, intuición individual y creativas soluciones que son difíciles de pasar y comunicar a otros. El conocimiento explícito podía ser tasado con el saber acceder a algo; mientras que el conocimiento tácito podría ser tasado como el saber cómo hacerlo.

Encontrar maneras para transferir el conocimiento tácito y explícito o el saber acerca de algo y el saber cómo, por medio de la organización es difícil, dado que el conocimiento que se acumula en las cabezas de los individuos y dentro de varias unidades organizacionales es de valor limitado hasta que es compartido con otras partes de la organización, tanto de manera vertical como horizontal. Aunque el conocimiento explícito puede ser fácilmente capturado y compartido en documentos, y por medio de todos los sistemas de tecnología de información, casi el $80 \%$ por ciento de los conocimientos valiosos de la organización pueden ser conocimiento tácito el cual no es fácil de capturar y transferir.

Existe dos enfoques para la administración del conocimiento y que resultan críticos para el manejo de los administradores, primero se requiere establecer una cultura mental dentro de la empresa que motive la colaboración y segundo el compartir conocimientos con el personal como el conocimiento otorga poder a las personas dentro de las organización, por esta y otras razones a veces se produce un fuerte impulso por guardarlo en vez de compartirlo; el conocimiento de los administradores usualmente requiere grandes cambios en la cultura. Por ejemplo: para obtener nuevos objetivos estratégicos; una empresa construyó una sofisticada red basada en Internet de conocimientos; de esta manera, los empleados podían compartir conocimientos por medio de intranet corporativa. Sin embargo, la parte más difícil del proceso fue el cambio hacia una cultura de colaboración y de compartir conocimientos. El Gerente General para implantar el cambio cultural tuvo que emplear medidas muy originales de motivación; para ayudar a los empleados a entender sus nuevos papeles y responsabilidades y como el compartir conocimientos puede beneficiarlos a ellos y a la organización.

El primer enfoque para la administración del conocimiento trata principalmente de coleccionar y compartir el conocimiento explícito utilizando sofisticados 
sistemas tecnológicos de información. Este conocimiento puede incluir propiedades intelectuales como patentes y licencias, procesos de trabajo, también información específica de clientes, mercados, proveedores o competidores, reportes de inteligencia competitiva e información de benchmark.

Cuando la organización utiliza este enfoque, se concentra en coleccionar y codificar conocimiento, para después almacenarlos en una base de información donde puede ser de fácil acceso y utilizada por cualquier empleado de la organización. Con este enfoque el conocimiento es reunido por los individuos que lo poseen y es organizado en documentos a los que otros pueden tener acceso y usarlo.

El segundo enfoque se concentra en influenciar la experiencia individual y el saber como hacer; este conocimiento tácito conecta a las personas cara a cara o por medio de comunicación interactiva para un trabajo más profesional; por tanto incluye la creatividad, la intuición individual, la experiencia personal y la perspicacia. Con este enfoque, los administradores se concentran en desarrollar redes de comunicación personal que conectan gente para compartir el conocimiento tácito.

La organización utiliza los sistemas de tecnología de información principalmente para facilitar la conversación y el poder compartir una experiencia persona a persona, intuición e ideas. Por ejemplo las intranets son muy importantes para ayudar a los empleados, compartir ideas y tocar el conocimiento de expertos por medio de la organización. Un ejemplo sería cuando un empleado necesita localizar a alguien con experiencia en una industria en particular; esa persona simplemente escribe en una computadora una pregunta, la cual es enviada automáticamente a todos los empleados a través de intranet. Asimismo también se pueden juntar personas mediante reuniones de equipo cara a cara o por medio de video conferencias para conversaciones intensivas.

En general, las organizaciones pueden combinar varios métodos y tecnologías para facilitar el compartir y transferir el conocimiento explícito y el tácito. 